\title{
In a War with the Virus: Science, People and Politics
}

\author{
Deepak Gupta \\ Strategic Communication \& Programmes - UN system in Asia and the Pacific Regions - drguptad11@gmail.com
}

\begin{abstract}
The world, attacked by a malicious virus in the last quarter of the year 2019 termed it as SARS-CoV-2 (WHO) and manifestation of the 'disease' caused due to this virus was dubbed as COVID-19. Transmitting through respiratory-tract, it has already impacted millions of people, with a high mortality in vulnerable age groups.

It is reckoned that the outbreak of COVID-19 pandemic is a major public health concern with equally dire health consequences with critical environmental and economic impacts. Scientific community developed multiple vaccines and repurposed drugs for the COVID-19; however, the vaccination against this pathogen still throws a huge challenge of low uptake

to COVID-19 vaccination programme, i.e. ensuring equitable access and the positive behaviour change marketing strategies.

People acknowledge that this pandemic is primarily a 'behavioural practices' issue, including at community levels. The outrage of the 'infodemic' (spread of misinformation) is gaining currency especially through social media and digital space.

The technical area of health communication has assumed a high-level of tilted 'political communication' in many countries. It is, therefore, time to witness more of science in politics than politics in science.

The article includes a key informant interview with a former WHO expert.
\end{abstract} across the world. There are two dimensions

Keywords: vaccine-hesitancy, inequity in immunization access, pandemic behaviours, social \& behaviour-change.

\section{Em Guerra com o Vírus: Ciência, Pessoas e Política}

\section{Resumo}

O mundo, atacado por um vírus malicioso no último trimestre do ano de 2019, chamou-o de SARS-CoV-2 (OMS) e a manifestação da 'doença' causada por esse vírus foi apelidada de COVID-19. Transmitindo-se pela respiração, já afetou milhões de pessoas, com alta mortalidade em faixas etárias vulneráveis. Estima-se que o surto da pandemia COVID-
19 é um grande problema de saúde pública, com consequências igualmente terríveis para a saúde, com impactos ambientais e económicos críticos. A comunidade científica desenvolveu várias vacinas e medicamentos reutilizados para o COVID-19; no entanto, a vacinação contra esse patógeno ainda representa um grande desafio de baixa absorção em todo o

(C) The Author(s) 2021. Open access article published online by Interações: Sociedade e as Novas 130 Modernidades, ISSN: 2184-3929, at https://interacoes-ismt.com, under the terms of the Creative Commons Attribution-NonCommercial 4.0 International Licence (https://creativecommons.org/ licenses/by-nc/4.0). 
mundo. Existem duas dimensões no programa de vacinação COVID-19, nomeadamente, garantir o acesso equitativo e desenvolver estratégias de marketing de mudança de comportamento positiva.

As pessoas reconhecem que esta pandemia é principalmente uma questão de 'práticas comportamentais', inclusive em nível comunitário. A indignação do "infodémico" (disseminação de desinformação) está a ganhar popu- laridade, especialmente por meio dos média e do espaço digital. A área técnica de comunicação em saúde assumiu um alto nível de "comunicação política" enviesada em muitos países. É, portanto, hora de testemunhar mais da ciência na política do que da política na ciência.

$\mathrm{O}$ artigo inclui uma entrevista com um informante-chave, ex-especialista da OMS.

Palavras-chave: hesitação de vacina, desigualdade no acesso à imunização, comportamentos pandémicos, mudança social e de comportamento.

\section{INTRODUCTION}

The humanity was mercilessly invaded by a virus in the later months of the year 2019. This pathogen was termed as SARS-CoV-2 (belonging to the family of Corona viruses)(Tang et al., 2020) by the World Health Organization, wherein the manifestation of the 'disease' caused due to this virus was dubbed as COVID-19. With its transmission route primarily being through respiratory-tract - like many other pathogens causing Influenza - it has managed to adversely impact millions of people, including with a very high mortality in some vulnerable age groups and people with co-morbidities.

The outbreak which initially, as documented so far, occurred in a seafood market in Wuhan, China spread across countries through human-to-human transmission and the subsequent community spread within a short period (WHO, 2020 cited by Sarkodie \& Owusu, 2020). Simultaneously, on March 11, 2020, WHO declared COVID-19 as a global pandemic after the infectious viral disease spread across 114 countries with 118,000 confirmed cases and 4291 deaths (WHO, 2020 cited by Sarkodie \& Owusu, 2020). Within the first quarter of the year 2020, the national governments braced up to learn about the entirely 'unknown threat' that had descended upon, thus causing fear, insecurity and helplessness of the health systems in coping up with the rapidly growing numbers of human morbidities and mortality due to the COVID-19 infections. 


\section{THE NEXUS: HEALTH CONSEQUENCES, ENVIRONMENTAL AND ECONOMIC IMPACT}

In the absence of available therapeutics and vaccines to contain this new virus until early 2021, a number of prevention behavioural practices were propagated by the scientists and clinicians. These included, maintaining physical distance with other individuals of at least 6 feet, frequently washing hands with soap and water, and wearing a face mask. The practice of social distancing, though still not strictly adhered to in most settings, and the other significant corrective measures to contain the spread of COVID-19 through human-to-human transmission has its own environmental, health and economic impacts. While the global pandemic has led to an ostensible enhancement of the health system and a relative decline of carbon emissions, economic development surely is the casualty and hence, deteriorating. Therefore, wherein the air pollution has demonstrated a global decline during the pandemic, health related municipal and medical waste has witnessed a steady increase. Science, innovation, research and development underpin COVID-19 containment measures implemented across countries. The emergence of the novel coronavirus, i.e. SARS-CoV-2 resulting in COVID-19, as a global pandemic once again triggered the necessity of reckoning the environment-health-economic nexus. Therefore, the outbreak of COVID-19 pandemic is a public health concern with an equally dire health consequences and highly critical environmental and economic impacts (Wang, Horby, Hayden, \& Gao, 2020).

During the ongoing period of the global pandemic, multiple measures have been enforced in order to contain the further spread of COVID-19 (Gautam \& Trivedi, 2020). Some of the many such measures include quarantine, continued travel bans and restrictions, social (physical) distance enforcement and lockdown of a large geographical area such as city, town or a certain village, which yields complete closure of public places. These containment measures put in place to reduce health outcomes of the global pandemic have adversely impacted sustainability and economic development. Many studies are demonstrating the environmental impact of COVID-19, however no study has yet explicitly informed on the larger health and economic implications of the global pandemi (Gautam \& Trivedi, 2020). 


\section{ODYSSEY OF VACCINE RESEARCH,TREATMENTS AND LAUNCH}

With an outbreak of the novel corona virus disease COVID-19 in the later months of 2019, caused by the SARS-CoV-2 virus, it has spread rapidly around the globe. Considering the potential threat of a pandemic, scientists and physicians were racing to understand this new virus and the patho-physiology of this disease to quickly discover every possible treatment regimens together with effective therapeutic agents and vaccines (Liu et al., 2020).

Scientific research has classified four classes of corona viruses termed as alpha, beta, gamma, and delta. The beta corona virus 'family' includes severe acute respiratory syndrome (SARS) virus (SARS-CoV), Middle East respiratory syndrome (MERS) virus (MERS-CoV), and the COVID-19 wherein the causative agent is SARS-CoV-2. This is similar to SARS-CoV and MERS-CoV, SARS-CoV-2 that attacks the lower respiratory system to cause viral pneumonia, but it may also affect the gastrointestinal system, heart, kidney, liver, and central nervous system leading to multiple organ failure (Zhu et al., 2020), as is documented through multiple layers of clinical findings.

The world community put forth a concerted effort in developing effective drugs and vaccines against the existing and potential future corona virus infections and other highly pathogenic virus outbreaks in the beginning of the year 2020 itself. It was indeed a desperate response. And it was necessary to reduce overwhelmingly drastic impacts on human life and worldwide healthcare systems, which continues to remain weak. As is experienced, the costly and relentless process involved with the clinical drug development, the COVID-19 pandemic further highlighted the value of developing relatively broad-spectrum antiviral drugs and the critical need for applying innovative approaches such as artificial intelligence to further facilitate studies on discovering appropriate drugs. Due to the long drawn and lengthy processes of new drug development, the employed strategy of drug repurposing became one of the chosen solutions for immediate treatment of SARS-CoV-2 infected individuals in 2020 .

During the early months of the onset of the pandemic, 175 patents emerged and disclosed vaccines for non-corona viruses that may have relevance to SARS and MERS, wherein 188 patents were directly associated with anti-SARS and anti-MERS vaccines with a good immune response (Richardson et al., 2020). In the initial months of vaccine research and development, 15 patents disclosed information about inac- 
tive and live-attenuated virus vaccines, 28 patents described DNA vaccines, 21 patents disclosed information on viral vector vaccines, 13 patents disclosed information on VLP (virus like particle) vaccines, and three patents focused on mRNA vaccines.

Needless to emphasize, it was crucial and equally critical, to develop safe and effective vaccines to control the COVID-19 pandemic, eliminate its very spread, and in the endcontrol its future recurrence. As research demonstrates, the SARS-CoV-2 virus shares significant sequence homology with two other lethal corona viruses, i.e. SARS and MERS, the vaccines identified in these patents related to SARS and MERS viruses were also potentially considered in facilitating the design of anti-SARSCoV-2 vaccines. The key to management of the pandemic is the optimum delivery and uptake of vaccines, whichever 'product/make' is accessible to the communities in each country.

\section{COVID-19 VACCINATION - BOTTLENECKS AHEAD}

The global vaccination coverage of routine immunization remains at around $85 \%$, with no significant change visible in the past several years. It has rather deteriorated in the recent years. A considerable large size of population continues to pose a major challenge as it suffers from limited access to immunization services. The gap in immunization coverage, both amongst well and poorly performing countries, is widening annually. For example, polio still continues to be endemic in a couple of countries, while the newer vaccines, such as for COVID-19, still throw a challenge of low uptake in many regions across the world. Poor access to health facilities, or a complete lack of it, for vaccination programmes, insufficient and inappropriate use of available resources, poor technical capacity and least empowered immunization decision-making bodies, lack of political will, civil conflict and war, and natural disasters - all of these contribute to under-immunization. Therefore, there are two dimensions to COVID-19 vaccination programme, i.e. ensuring equitable supply/access and logistics and the 'demand-generation'/positive behaviour change marketing strategies.

The public health programmes have been struggling for many decades in reaching out to communities and delivering the vaccination programmes. Despite the efforts invested in the supply aspects of vaccinations, social scientists continue to face challenges with the demand generation dimensions of the immunization programmes. 
Social scientists are facing an uphill task of ensuring optimum vaccine uptake in many communities (Gupta, Agarwal, \& Bhasin, 2019). Therefore, while supply and logistics throw challenges in ensuring equity i.e. equitable access to all, a significant emphasis on the 'health seeking behaviour' aspects in communities also plays a significant role in achieving nearly cent percent immunization coverage. COVID-19 vaccination is no exception; as it is already posing a mammoth logistics' challenge for the health systems in the countries. Yet, in some select communities the demandgeneration aspects, i.e. making communities accept COVID-19 vaccination remains a major bottleneck for the political leadership and health communication experts.

\section{ADDRESSING AN UPHILL TASK: PANDEMIC APPROPRIATE BEHAVIOURS}

Multiple scientific studies demonstrate that much of the growth in the field of health communication was stimulated by the AIDS response which started in the decade of 80 s, especially when there was no antiretroviral treatment (ART) available and the only tool on hand was prevention through focused social and behaviour change. It is also noteworthy that the earlier gathered communication lessons and experiences for improving maternal \& child survival and for encouraging family planning underpinned these early HIV prevention communication strategies. Clinicians, scientists and communication experts are emphasizing on how people need to strictly adhere to pandemic appropriate behaviours, such as hand-washing, face masking and physical distancing, including ensuring getting a jab in the arms - whenever it's accessible. Preventive behaviour is the key to emerging out of the pandemic as recommended by the health experts. Therefore, current pandemic is primarily a 'Behavioural Practices' challenge which can well be managed by the strategic communication strategies under the already well researched Risk Communication \& Community Engagement (RCCE) model.

Most people have reckoned that this pandemic is primarily a 'behavioural practices' issue, both at individual and at community levels. As a result, such people will adopt practices as are being disseminated by the credible and trusted sources. Yet, there will always be a few hard-core 'laggards' who defy acceptance of any positive change. Such segment of population, of course, have their own reasons based on myths, rumours or incorrect beliefs. Conspiracy theories and a vast sea of misin- 
formation is playing abound, though it was at-work even before the launch of the COVID-19 vaccination drives. The outrage of the 'infodemic' (spread of misinformation during pandemic) is gaining currency especially through social media and digital space. People ought to understand that this virus is an absolute new pathogen which is, even after over a year, still being researched and studied, including its fast emerging mutants. Therefore, in the initial months of the pandemic, the leading health agencies, respective national health departments, scientific community, clinicians and epidemiologists struggled to find out the more realistic mode of transmission, correct therapeutic/clinical treatment protocols and the research on vaccination. The initial bottlenecks included delay in declaring the pandemic and the immediate next was discouraging use of face-masks barring exception of health providers! Promoting 'avoidance of face-masks', nevertheless did a huge damage, during the pandemic's evolutionary months, leading to unchecked spread of virus.

\section{'PELTZMANEFFECT' - \\ A CHALLENGE TO RISK-COMMUNICATION EXPERTS: IMPACTING BEHAVIOURAL PRACTICES}

Right from the onset of the current pandemic, populations across the globe have become familiar with the concept of "risk compensation". In other words, in most situations which are perceived as risky, individuals tend to adjust their respective behaviours, thus compensating to minimize that specific risk. Therefore, people who perceived the SARS-CoV-2 as a major threat to health, in most cases, would wear appropriate masks, wash their hands regularly, and maintain physical distancing by avoiding large crowds, especially when cases began to surge. However, the effects of risk compensation tend to dilute away over time as the 'fear and risk' threat start wearing off.

With the gradual rise in COVID-19 cases across the continents, which is attributed to the possible "pandemic fatigue," also observed is the decreasing adherence to risk reduction strategies in many populations. It is further adding to complications in public health efforts.

With the start of the year 2021, COVID-19 vaccines were rolled out across the globe, which surely created much needed optimism and euphoria. However, public health experts and risk-communication professionals will have to be appraised of another vital feature of risk compensation. It is noteworthy that the vaccine nearly 
served as the panacea to the pandemic risks; therefore, further weakening the critical adherence to other pandemic appropriate behaviours, like regular hand washing/ sanitizing, physical distancing and face-masking. This phenomenon, in which individuals respond to safety measures with a compensatory increase in risky behaviour, is named the "Peltzman Effect" after University of Chicago economist Sam Peltzman who first described it in 1975 (Hedlund, 2000).

Even at a subconscious level, those who have not received a vaccine may slack in wearing face-masks and in maintaining physical distancing in crowded places, when these people know that others are receiving the vaccine for a last few months. Therefore, as the number of people who are vaccinated increases, the Peltzman effect may also evolve due to a higher misplaced sense of security in an assumed 'herd immunity' much prior to the expected widespread immunity is truly present in the communities. Hence, it throws a challenge to the communication experts and public health teams because, unfortunate that it is, the very optimism that is essential to encourage widespread acceptance of the vaccine shall undoubtedly end-up contributing to the overconfidence among people, which can ultimately worsen this effect.

It is critical to understand that for the current pandemic, a Peltzman Effect may manifest in varied ways for different groups of populations, including patients. Widespread misinformation and a highly politicized public health landscape have resulted in a wide spectrum of behaviours in response to COVID-19 (Kim, Marks, \& Clemens, 2021). Among those who refuse to practice pandemic appropriate behaviours - the "anti-maskers," or those who reject social-distancing guidelines - the Peltzman Effect will be nil.

Social and behavioural scientists have been contemplating whether or not the COVID-19 vaccinations would result in increased risk-taking behaviour? A set of studies sought to seek answers within the context of the Peltzman Effect. It therefore, identified four lead factors as the possible contributors to risk compensation, while these are apparent in the COVID-19 pandemic (Kim, Rowland-Jones, \& Gea-Mallorquí, 2020). Undeniably to present an increase in a risky behaviour, a measure must first be 'visible', this is the criterion well met with the COVID-19 vaccination due to discussions and publicity it has generated world over. Every individual who receives the vaccine will be very well aware that they have done so. The subsequent two points, i.e. 'motivation' and 'control' - go together. Risk compensation is more likely to occur if people are highly motivated to take on the risky behaviour and if it is within their control to do so. Naturally, both of these well apply to the current pandemic, because 
it is both personally desirable and relatively easy to return to a pre-pandemic lifestyle free of face-masks and physical distancing. And the final factor, which is the overall 'effectiveness' of the intervention, entirely depends on the vaccine.

Unfortunately, it is observed that the highly technical area of public health communication, in case of health emergencies and disasters the risk-communication, is still being largely managed by the 'generalists' and in some contexts, even has assumed a high-level of tilted 'political communication' in many countries. However, it's time to witness more of science in politics than politics in science!

\section{A CRITICAL DENOMINATOR: RISK COMMUNICATION \& STRATEGIC HEALTH COMMUNICATION}

The overall paradigm of strategic health communication remains uniform, while the core methodologies, communication content and outreach strategies change in case of disasters, pandemics and outbreaks. For example, we cannot strategise to communicate pandemic messages the way we design communication interventions for sexual \& reproductive health (SRH), age-at-marriage, family planning or even promoting breastfeeding. Some risk communication frameworks have been potentially employed in deciphering the challenges of wide-spread disease control and pandemics. When people are really concerned, stressed, or outrageously upset, they want to know that you care before they care what you know (Trust Determination Theory); when people have difficulty in hearing, understanding, and remembering bulk of information and thus they focus most on what they hear first (Mental Noise Theory); and again when people are highly stressed, or upset, they often focus more on the negative than on the positive (Negative Dominance Theory); similarly, the gaps between risk perceptions and reality often become wider during such difficult times (Risk Perception Theory) (Renn \& Levine, 1991).

At different stages of pandemic or an outbreak, these core communication frameworks serve as a common denominator in planning and designing targeted activities. Unfortunately, most agencies are either withholding or rolling-out bulk of information without paying apt attention to its purpose, without clearly understanding the risk-factors' profile of its focused target audiences and missing out in addressing the critical gaps in tailoring of messages.There is a need for local leaders, trusted and credible celebrities to reach out to masses with customised do's and don'ts. For com- 
munication experts, it's critical to observe that the leaders not wearing an appropriate face-mask on TV are popularizing a rather dangerous trend leading to a risky behavioural practice in these pandemic times.

It can be easily construed that the success of risk communication of the pandemic is dependent on: (1) Timeliness of communication, (2) Simplicity, directness and consistency of the message, (3) Appropriateness of the selection of channels/tools, (4) Transparency in information sharing, and (5) Public faith and trust in the communicator (Gupta, Jai, \& Yadav, 2021).

\section{VACCINATION - EQUITY IN DISTRIBUTION | INTERNATIONAL DIPLOMACY}

As per the available records by middle of March 2021, over 20 million doses of COVID-19 vaccines have been donated directly to 81 low and middle-income countries, as part of rapidly growing vaccine diplomacy. India and China are leading the charge, now in almost direct competition to be viewed as the most generous vaccine donor. As on March 18, India that prefers to grant vaccines, has announced 8.1 million doses directly supporting 37 countries; whereas China has donated 7.9 million doses of COVID-19 vaccines to 33 countries. In comparison to China, India's vaccine diplomacy is not entirely focused on a locally developed vaccine; instead it is a locally manufactured one, i.e. Covishield (by AstraZeneca) - an Indian produced vaccine.

Under its vaccine outreach initiative, the immediate focus for India has been its neighboring SAARC countries; wherein Afghanistan and Sri Lanka have each received 500,000 doses, Nepal 1 million, Myanmar 1.7 million, and Bangladesh 2 million. However, India is now expanding upon their immediate region. For some manufacturing countries, such as India and China, supporting global mechanisms including COVAX in disseminating vaccines has also been a priority. India has supported the vaccine delivery of an additional 16.5 million doses through the GAVI run COVAX initiative.

As per the data available on 18 March, 2021, an additional 10 countries have announced direct donations of vaccines to countries: Australia, Barbados, Chile, Dominica, Israel, Romania, Senegal, Serbia, United Arab Emirates, and Venezuela.Australia is the third-largest donor with a grant of 3 million COVID-19 vaccines, specifically supporting Cambodia and 8000 to Papua New Guinea. Similarly, the UAE donated 670,000 doses of Sinopharm and Sputnik V to various countries in Asia and Africa. 
The author engaged with a leading epidemiologist and the former WHO Director, Dr. Jai. P. Narain ${ }^{1}$ in a direct conversation - a KII ${ }^{2}$ - on varied aspects of the current pandemic, including on vaccine skepticism and hesitancy for COVID-19 jabs in the arms and filling-in the communication gaps therein. A few excerpts are reproduced below:

1) Dr. Narain, the SARS-CoV-2 infections are swinging in waves world over, especially it came more as a rude shock when most people perceived that humanity is getting very close to winning this war with the virus. Why are we experiencing such a trend? And how far are the mutant viruses actually responsible for such a state of upswing?

Answer (JPN): I believe, there is no one single factor but multiplicity of factors responsible for the current wave of COVID-19. Most important of all perhaps is the sense of complacency and the pandemic fatigue set in among people as they have had to endure restrictions over a long period of time. As a result, people are no longer following the basic Covid prevention protocols such as mask wearing, social or physical distancing and hand hygiene. Given that most societies, such as in India, staying away from social gatherings, like family gatherings or from sports events and festivals which create a conducive environment for the pathogens and a fertile ground for the diseases transmission. Moreover, young people seem to feel that it cannot happen to us' and do not follow the Covid-appropriate behavior, putting elderly at home at a much higher risk.

The emergence of new strains of coronavirus, also called variants in many countries such as UK, Brazil and South Africa is of great concern as these are at least 50\% more infectious and could at times be more deadly. Addressing all these factors expeditiously is therefore, critical if we are to contain the spread as soon as possible and sustain our gains over time.

2) Scientific teams have varied opinions as regards whether or not the origin of the pathogen (SARS-CoV-2) was through Wuhan in 2019. Don't you think it's important to study the virus's origins, wherever it emanated from, and thus, aid further studies in

1 Formerly Director of World Health Organization, SEARO; Ex Sr. Advisor, Government of India on Epidemiology and EIS (Epidemic Intelligence Service); Global Health Advisors Alliance

2 Key Informant Interview (KII) 
learning how this pathogen evolves further? It just might be more useful in determining stopping of its mammoth spread.

Answer (JPN): Yes, indeed! Understanding the origin is crucial as such information can help understand natural history of disease and to find ways to prevent current and future pandemics. In this pandemic, the specific mechanisms of its emergence in humans remain unknown. Discovering where the virus came from could help scientists understand how the virus most likely got introduced into humans and teach public health leaders how to avoid such situations.

Scientists and epidemiologists have been issuing repeated warnings for decades that multiple viruses are poised to emerge again and again, thus challenging public health as never before. They also called for enhanced pandemic prevention and control efforts through building core capacities in epidemiology and laboratory diagnosis. This was borne out by emergence of novel Coronavirus in 2019 in China, which quickly spread world over. The risk of similar Coronavirus or influenza viruses emerging in the future remains high and needs appropriate steps be taken by all countries. Inter-country collaboration is also important to share information, expertise and essential supplies to minimise the health and social impact of the pandemic.

3) Needless to emphasize, management of this pandemic is a clear commentary on political governance, health systems in each country and every nation's preparedness for addressing such health emergencies. It even reflects how much of national resources were and are being allocated under the health budgets, including for any possible health emergencies. Although the virus has somehow managed to invade nearly every corner of the globe, a few handful of nations have managed its spread, prevention strategies and clinical treatment better than the most others. How do you view this situation and how do we foresee the future priorities for the countries?

Answer (JPN): Many lessons have been learnt from this pandemic. Most importantly, it has highlighted on the urgent need to invest in public health now and in the future. In many countries, expenditure on health as percentage of GDP is abysmally low. This must change; otherwise we will not be in a strategic position to fight the emerging infections. We also need to build a strong and robust health system and emergency management capacity as a backbone of health response, as is also required under IHR (2005). And embrace modern technology such as big data management, 
and communication and information technology including use of social media for good and meaningful impact. International collaboration and coordination in science and technology can help rapid sharing of disease data and scientific progress, ensuring development and equitable access to new diagnostics, treatment and vaccines. Finally, it has highlighted the need to focus on behaviour change communication, building trust and community engagement as an integral part of the 'holistic society approach' as bedrock of disease prevention. These are just a few examples.

4) We need to reckon the fact that immediately after the SARS-CoV-2 cases were detected, initially in Wuhan and subsequently across many countries in Europe, the technical guidance from the DG-WHO publically emphasized that masks are not for general public, instead only the health providers should ensure use of appropriate face-masks. Many weeks and months were lost in this dilemma until such time when it was again propagated that every individual must practice wearing a three-layered face mask covering. Do you think much damage was already done then with such public messaging?

Answer (JPN): As stated already that SARS-CoV-2 was an entirely new virus detected only a year ago. We are still trying to understand the virus and its characteristics, its transmission dynamics and how to better manage and prevent it. As we gradually began to understand the science behind the disease, the recommendations on how to prevent have also evolved. The recommendations by WHO during early part of the pandemic that masks are not meant for general public, instead only for health care workers, was based on the priority setting keeping in view the availability of logistical supplies and existing capacities to quickly produce them. Since health care workers were and continue to remain at a greater risk of COVID-19, hence the need to ensure that health workers get the precedence in receiving limited available supplies.

5) Vaccination, to mitigate the current pandemic, has been developed by the scientific community at an unprecedented speed. However, there are issues emerging after these are being rolled out, especially so in respective governments' ability in effective roll-outs, ensuring supply chain and strategically covering the needs of the communities. What do you think are the reasons for such supply management issues?

Answer (JPN): In keeping with the pace at which the virus was spreading around the world, the science too has made an unprecedented progress in developing vac- 
cines at a record time and the roll out is already underway in many countries. There are however, supply and demand issues resulting in gross and unacceptable inequity in vaccine distribution and access in the world. Many countries have resorted to 'vaccine nationalism' as rich countries purchasing most of the global vaccine supplies -- a few countries have ordered the amount enough to vaccinate their populations many times over, while most low and mid-income countries are at risk of going without vaccine for their populations.

On the other hand, India which produces two of the vaccines indigenously has been generous in donating vaccine to many countries in Asia, Africa and Latin America. Contribution by India to WHO-coordinated COVAX facility is ensuring global access to vaccines and trying to bridge the gap between supply and demand. The world's dependence on India for the vaccine can be seen from the fact that as many as 84 countries have so far received India-made vaccines, either through grant, commercially or via WHO’s COVAX programme. By the middle of March 2021, India had exported more vaccine doses than that administered at home.

6) Refereeing to the vaccination again, there are still many individuals and communities that are hesitating in taking the jab in their arms. Vaccine hesitancy remains yet another missing link in addressing this pandemic. What do you think should be an effective strategy in ensuring that vaccines are widely accepted?

Answer (JPN): The issue of vaccine hesitancy and the reasons behind it are complex. The reluctance to accept vaccination has occurred especially during the initial stages of the vaccination programmes. Hence, understanding and communicating with those who have doubts about the COVID-19 vaccines and explaining in the personal risk and potential benefits associated with vaccination holds the key. Some of the steps for addressing vaccine hesitancy include communication and building trust, being honest about side effects upfront prior to the jab, providing re-assurance on a robust vaccine safety and effectiveness, with focusing on protection of self as well as the community.

It is to be clarified that the number of vaccine-hesitant individuals far outnumbers those who refuse the vaccine; therefore, counselling of or one-on-one communication with this group might be more effective. The reasons behind vaccine hesitancy go beyond just a knowledge deficit. In some cases, these have political dimensions too. Nevertheless, health care physicians as a trusted source of information can play a key role in driving vaccine acceptance. 
7) As we know that there are certain vaccine manufacturing hubs in the world. With the knowledge transfer taking place between scientists, researchers and pharmaceutical companies, many countries are still far from receiving the required vaccine doses for their populace. How best, do you think, the vaccine distribution should be organized that ensures equitable dissemination of supplies?

Answer (JPN): In many low- and middle-income countries, vaccination has not even started which is a catastrophe as hospitals fill up with COVID-19 cases. Swift action is needed to correct this injustice. The best way to end this pandemic, stop future variants and save lives is to limit the spread of the virus by vaccinating quickly and equitably, starting with health workers. This is why WHO called this a catastrophic moral failure, the price of which will be paid, unfortunately, with lives and livelihoods in the world's poorest countries.

To ensure the vaccine equity, all countries must make vaccination a priority and work together in solidarity to ensure that vulnerable populations in all countries are protected first of all. WHO too has issued a call to action and for support to COVAX facility created in partnership to facilitate rolling out of vaccines quickly and equitably at a global level. In this endeavor, the world leaders, vaccine manufacturers, regulatory bodies, ministries of health and all governments have a pivotal role to play in their respective areas.

8) In order to emerge unhurt or least affected out of this pandemic, what would be your strong recommendations for the specific groups, i.e. national governments, community leaders, health workers and the people?

Answer (JPN): To end this pandemic and save economies, it is critical to strictly follow basic COVID-19 precautions, expand testing, tracing and treatment strategy, and vaccinate populations quickly. To do so, health must be foundational or central to all the development policies and investing in primary health care as a key strategy for ending this pandemic and preparing for the next one.

I should like the national governments to invest urgently in public health in particular epidemiology and laboratory services, enhance health workforce capacity building, and develop data systems on disease trends and vaccine supply, distribution and ensure delivery and equitable access for all those who need it. It is critical for Ministries of Health to develop core capacity at all levels of health services to 
be able to detect early and respond rapidly to public health emergencies. Intensified implementation of the 3T strategy of 'test, track and treat' is fundamental to disease prevention and mitigation. The community leaders and people have the responsibility to continue taking Covid precautions such as wearing a mask, avoiding crowded places, washing hands frequently, and practicing social distancing. And equally critical, get vaccinated with two doses as recommend to protect self, their families and others in the society.

And finally, we must augment funding substantially for public health action and for basic and applied research including on disease emergence to prevent such tragic events from occurring again.

\section{CONCLUSION}

Global COVID-19 curve is being closely watched by the respective governments, international development actors and health experts. Urgent answers are needed to the questions that are being asked about the challenges before the governments and health experts, the envisaged role of communication in spreading awareness and bringing sustained behaviour change about Coronavirus, its implications and vaccine related research. It includes critical need for fostering innovative approaches, as deem required, for managing equitable supplies and logistics of COVID-19 vaccination and the demand generation and heightened use of these vaccines in the communities, especially the vulnerable, socially excluded and hard-to-reach populace.

It is well established that the post-COVID-19 era is expected to rekindle and further foster environmental degradation, while improving and sustaining the health system to recover and rebuild livelihoods and thus, ensuing economic productivity. On the contrary, it is also demonstrated that the after effects of the pandemic will have a sustained societal effect on offices/workplaces, public places and social and cultural events, which shall, in turn, directly impact the economic transition. Therefore, governmental efforts across the globe are required to strike a fine balance between environmental sustainability, health outcomes and sustained economic development due to the potential post-pandemic effects; this is more so keeping in view the commitments made by the governments and the international development partners under the Agenda 2030 of the Sustainable Development Goals (SDGs). In nutshell, not political but scientific logic should determine the pathways of public health and the key decisions being made with regard to the current scourge on humanity, i.e. the COVID-19 pandemic. 
Varied infectious diseases, especially resulting from RNA viruses subject to multiple mutations and genetic recombination, as well as cross-species transmission, will continue to throw up a challenge of a serious global health threat, as is viewed by the scientific community. This is also exemplified by the ongoing pandemic of COVID-19. As was witnessed during the two former major outbreaks of coronavirus infections that caused the SARS and MERS respiratory illnesses, unfortunately the world continues to remain under prepared to effectively manage the current COVID-19 outbreak. It is widely evidenced by the fact that COVID-19 has already resulted in hundreds of thousands of human mortalities worldwide, needless to mention a much greater number of serious and long haul morbidities. While vaccinations offer a partial respite to the humanity from serious morbidities and infection causing death, the most effective weapon against the virus remains 'Prevention', i.e. continued adherence to key pandemic appropriate behaviours, though making a choice between 'livelihoods' and 'life' is a serious question that still looms large.

Time is now when the people out rightly need to invest full faith in science. In other words, people need to assimilate and follow what the scientific community is propagating, while the politics of pandemic has no space in the global war against the drastic virus.

Declaration of Conflicting Interests: The author declared no potential conflicts of interest with respect to the research, authorship and/or publication of this article.

Funding: The author received no financial support for the research, authorship and/or publication of this article.

\section{REFERENCES}

Gautam, S., \& Trivedi, U. (2020). Global implications of bio-aerosol in pandemic. Environment, Development and Sustainability, 22, 3861-3865. https://doi. org/10.1007/s10668-020-00704-2

Gupta, D., Hassan, B., Agarwal, A., \& Bhasin, A. (2019). Immunization Campaigns: Mitigating Barriers - Designing Communication. Interações: Sociedade e as novas modernidades, (36), 158-175. https://10.31211/interacoes.n36.2019.e2 
Gupta, D., Jai, P. N., \& Yadav, J. S. (2021). Strategic Communication in Health and Development: Concepts, Applications and Programming (SAGE). Journal of Health Management, 23(1), 95-108. https://doi. org/10.1177/0972063421994943

Hedlund, J. (2000). Risky business: safety regulations, risks compensation, and individual behavior. Inj Prev. 6, 82-90. [PMID: 10875661]. https://doi. org/10.1136/ip.6.2.82

Kim, D. S., Rowland-Jones, S., \& Gea-Mallorquí, E. (2020). Will SARS-CoV-2 infection elicit long-lasting protective or sterilising immunity? Implications for vaccine strategies (2020). Front Immunol. 11(571481). [PMID: 33362759] https://doi.org/10.3389/fimmu.2020.571481

Kim, J. H., Marks, F., \& Clemens, J. D. (2021). Looking beyond COVID-19 vaccine phase 3 trials. Nat Med. 27, 205-211. [PMID: 33469205]. https://doi. org/10.1038/s41591-021-01230-y

Liu, C., Zhou, Q., Li, Y., Garner, L. V., Watkins, S. P., Carter, L. J., Smoot, J., Gregg, A. C., Daniels, A. D., Jervey, S., \& Albaiu, D. (2020). Research and Development on Therapeutic Agents and Vaccines for COVID-19 and Related Human Coronavirus Diseases. ACS Cent. Sci. 6(3), 315-331 https://doi.org/10.1021/ acscentsci.0c00272

Renn O., \& Levine D. (1991). Credibility and trust in risk communication. In: R. E. Kasperson, \& P.J.M. Stallen (eds), Communicating Risks to the Public. Technology, Risk, and Society (An International Series in Risk Analysis), 4. https://doi.org/10.1007/978-94-009-1952-5_10

Richardson, P., Griffin, I., Tucker, C., Smith, D., Oechsle, O., Phelan, A., \& Stebbing, J. (2020). Baricitinib as potential treatment for 2019- nCoV acute respiratory disease. Lancet, 395(10223), e30-e31. https://doi.org/10.1016/S01406736(20)30304-4

Sarkodie, S. A., \& Owusu, P. A. (2020). Global assessment of environment, health and economic impact of the novel coronavirus (COVID-19), Environment, Development and Sustainability, 23, 5005-5015. https://doi.org/10.1007/s10668020-00801-2 
Tang, X., Wu, C., Li, X., Song, Y., Yao, X., Wu, X., Duan, Y., Zhang, H., Wang, Y., Qian, Z., Cui, J., \& Lu, J. (2020). On the origin and continuing evolution of SARSCoV-2. National Science Review, 7(6). https://doi.org/10.1093/nsr/nwaa036

Wang, C., Horby, P. W., Hayden, F. G., \& Gao, G. F. (2020). A novel coronavirus outbreak of global health concern. Lancet, 395(10223), 470-473. https://doi. org/10.1016/S0140-6736(20)30185-9

Zhu, N., Zhang, D., Wang, W., Li, X., Yang, B., Song, J., Zhao, X., Huang, B., Shi, W., Lu, R., Niu, P., Zhan, F., Ma, X., Wang, D., Xu, W., Wu, G., Gao, G. F., Tan, W., \& China Novel Coronavirus Investigating and Research Team (2020). A Novel Coronavirus from Patients with Pneumonia in China, 2019. The New England journal of medicine, 382(8), 727-733. https://doi.org/10.1056/NEJMoa2001017 